\title{
ANALISIS FAKTOR-FAKTOR YANG MEMENGARUHI INTENTION TO ADOPT PADA E-WALLET DI INDONESIA
}

\author{
Saka Wisnu Saputtera
}

Universitas Airlangga, Surabaya, Indonesia

Email: sakasaputtera@gmail.com

\begin{abstract}
Abstrak
Penelitian dilakukan dengan tujuan menganalisis beberapa faktor yang mempengaruhi intention to adopt pada e-wallet. Penelitian ini memakai metode kuantitatif. Pengumpulan 270 data responden didapatkan dengan cara penyebaran kuesioner. Teknik pengambilan sampel menggunakan teknik purposive sampling serta Structural Equation Modelling (SEM) digunakan sebagai teknik analis dengan menggunakan aplikasi AMOS 22.0. Hasil penelitian ini yaitu Perceived mobility adalah varibel yang paling signifikan diantara variabel lainnya. Walaupun responden mempunyai persepsi personal innovativeness yang tinggi dan perceived compatibility yang tinggi namun tetap beranggapan $e$-wallet gopay tidak mempunyai manfaat seperti apa yang mereka harapkan.
\end{abstract}

Kata Kunci: $e$-wallet; model penerimaan teknologi; inovasi pribadi; kompatibilitas yang dirasakan; niat untuk mengadopsi

\section{Abstract}

The study was conducted with the aim of analyzing several factors that influence the intention to adopt an e-wallet. This research uses quantitative methods. The collection of 270 respondents' data was obtained by distributing questionnaires. The sampling technique used was purposive sampling and structural equation modeling (SEM) was used as an analytical technique using the AMOS 22.0 application. The results of this study, perceived mobility is the most significant variable among other variables. Although respondents have a high perception of personal innovativeness and high perceived compatibility, they still think that the GoPay e-wallet does not have the benefits they expect.

Keywords: e-wallet; technology acceptance model; personal innovativeness; perceived compatibility; intention to adopt

Received: 2021-12-20; Accepted: 2022-01-05; Published: 2022-01-15

\section{Pendahuluan}

Pesatnya perkembangan teknologi membuat kehidupan di era sekarang ini semakin mudah, dan banyak aspek kehidupan yang berubah, terutama dalam bidang ekonomi. Dalam era perekonomian digital ini, semakin banyak inovasi produk maupun jasa keuangan yang muncul untuk memudahkan masyarakat mendapatkan akses pada

$\begin{array}{ll}\text { How to cite: } & \text { Saputtera. S.W (2022) Analisis Faktor-Faktor Yang Memengaruhi Intention To Adopt Pada E-Wallet Di } \\ & \text { Indonesia. Syntax Literate: Jurnal Ilmiah Indonesia, 7(1). http://dx.doi.org/10.36418/ Syntax- } \\ & \text { Literate.v7i1.5651 } \\ \text { E-ISSN: } & \text { 2548-1398 } \\ \text { Published by: } & \text { Ridwan Institute }\end{array}$


sumber pendanaan, tidak hanya melalui pendanaan secara konvensional namun dapat pula menggunakan sumber pendanaan digital (fintech). Menurut (Rizal, Maulina, \& Kostini, 2018) fintech merupakan suatu inovasi pada sektor finansial yang mendapat sentuhan teknologi modern, dimana transaksi keuangan melalui fintech ini meliputi pembayaran, investasi, peminjaman uang, transfer, rencana keuangan dan pembanding produk keuangan.

Di Indonesia sekarang ini penggunaan mobile wallet atau e-wallet semakin populer seiring dengan meningkatnya kebutuhan akan kegiatan transaksi secara digital. Gopay akan digunakan sebagai salah satu contoh e-wallet dalam penelitian ini. Berdasarkan dari (De Pascalis, 2021) gopay memiliki jumlah pengguna dompet elektronik terbesar di Indonesia berdasarkan hasil survei yang dilakukan pada responden sebesar 83,3\% pada tahun 2019.

Namun dibalik tingginya angka transaksi seperti kegiatan transfer, pembayaran tagihan serta manfaat e-wallet yang ditawarkan tidak sebanding dengan peningkatan jumlah pengguna $e$-wallet. Hal tersebut dapat dibuktikan dengan penelitian (Immanuel, 2019) yang menyatakan pada segmen pembayaran mobile di Indonesia, jumlah pengguna hanya diperkirakan akan mencapai 65,9 juta pada tahun 2024. Tentu saja angka tersebut masih dapat dikatakan belum optimal bila dibandingkan dengan kelompok usia produktif (15-64 tahun) sebanyak 185,34 juta jiwa Katadata (2020).

Di Indonesia, meskipun perkembangan $e$-wallet mulai tumbuh, namun beberapa masyarakat masih merasa aneh menyimpan uang mereka di perangkat ponsel. Maka dari itu beberapa industri perbankan belum mengembangkan aplikasi $e$-wallet secara optimal (Hatmawan, 2019). Berdasarkan permasalahan yang diuraikan diatas, penelitian ini akan menganalisi beberapa faktor yang mempengaruhi intention to adopt pada e-wallet. Faktor yang diusulkan sebagai pengaruh terhadap intention to adopt pada e-wallet berdasarkan penelitianan terdahulu yaitu perceived ease of use, perceived usefulness, personal innovativeness, compatibility, mobility, perceived security, subjective norm, dan trust.

Sebuah studi oleh (Shankar \& Datta, 2018) berjudul "Factors Affecting Mobile Payment Adoption Intention: An Indian Perspective" menggunakan kerangka konseptual berdasarkan Technology Acceptance Model (TAM) untuk mengkaji faktorfaktor yang mempengaruhi niat pembayaran mobile India untuk mengadopsi pembayaran atau mobile payment. Hasil yang diperoleh dalam penelitian ini adalah perceived ease of use, perceived usefulness, dan trust memiliki dampak positif yang signifikan terhadap niat adopsi m-payment. Perceived ease of use menjadi faktor penentu yang paling memengaruhi m-payment adoption intention di India karena pengguna dapat menerima m-payment hanya jika merasakan kemudahan dibandingkan dengan metode transaksi keuangan tradisional lainnya. Tetapi subjectif norm dan personal innovativeness tidak memiliki dampak signifikan pada niat adopsi m-payment karena m-payment dianggap sebagai saluran keuangan yang sama dengan m-banking sehingga tidak memerlukan pengetahuan khusus untuk dipahami.

A. Hubungan Personal Innovativeness dan Perceived Ease of Use 
Personal innovativeness dapat didefinisikan sebagai tingkat keinginan seseorang untuk mengadopsi suatu ide baru dibandingkan dengan orang lain (Septiani, Handayani, \& Azzahro, 2017). Personal innovativeness juga diakui dan dianggap sebagai faktor penting yang mempengaruhi kemudahan. Individu yang mempunyai tingkat personal innovativeness lebih aktif ketika mencari informasi dari sesuatu yang baru dan mereka mengadopsi inovasi lebih awal daripada yang lain atau bisa dikatakan sebagai pengadopsi awal. Maka dari itu pada penelitian ini menganggap personal innovativeness memiliki efek positif yang signifikan pada perceived ease of use pada m-payment. Sehingga berikut hipotesis yang diusulkan:

H1: Personal innovativeness secara positif memengaruhi perceived ease of use pada e-wallet.

B. Hubungan Personal Innovativeness dan Perceived Usefulness

Dalam teknologi, personal innovativeness adalah kemauan seseorang untuk mencoba teknologi baru. Individu yang mempunyai tingkat personal innovativeness tinggi lebih aktif ketika mencari informasi teknologi terbaru dan mereka berupaya mengadopsi inovasi lebih awal daripada yang lain dan menjadi sebagai pengadopsi awal. Individu dengan tingkat inovasi yang tinggi umumnya memiliki kesan dan manfaat yang positif terhadap teknologi, sehingga individu dengan tingkat inovasi yang tinggi akan kehilangan manfaat tertentu jika tidak mencoba teknologi baru (Nugroho \& Fajar, 2017); (Acheampong et al., 2017). Sehingga, penelitian ini menyimpulkan hipotesis sebagai berikut:

H2: Personal innovativeness secara positif memengaruhi perceived usefulness pada e-wallet.

C. Hubungan Subjective Norm dan Perceived Ease of Use

Pengaruh sosial dalam bentuk subjective norm sering digunakan sebagai faktor baik dalam model penelitian tentang pengadopsian teknologi terbaru. Subjective norm didefinisikan sebagai tingkat persepsi pribadi individu tentang apakah suatu sistem harus digunakan atau tindakan tertentu harus diambil, berdasarkan orangorang yang mereka anggap sebagai panutan. Ketika konsumen menemukan produk teknologi baru, mereka merasakan ketidakpastian tertentu atau mengalami keraguan tentang produk atau jasa yang baru dan konsekuensi dari penggunaannya (de Luna, Liébana-Cabanillas, Sánchez-Fernández, \& Munoz-Leiva, 2019). Maka dapat diusulkan hipotesis sebagai berikut:

H3: Subjective norm secara positif memengaruhi perceived ease of use pada e-wallet.

D. Hubungan Subjective Norm dan Perceived Usefulness

Subjective norm menekankan peran pendapat kerabat, teman, teman sebaya, atau orang yang dianggap penting karena pada tahap awal adopsi teknologi, sebagian besar konsumen merasa kurang memahami teknologi dan tidak memiliki cukup pengetahuan untuk mengevaluasi kegunaan, kemudahan penggunaan, serta keamanan. Akibatnya, konsumen cenderung mengikuti norma sosial dalam 
keputusan adopsi teknologi mereka (Schierz, Schilke, \& Wirtz, 2010). Maka hipotesis yang diusulkan:

H4: Subjective norm tinggi secara positif mempengaruhi perceived usefulness pada e-wallet.

E. Hubungan Perceived compatibility dan Perceived Ease of Use

Compatibility memiliki arti yaitu seberapa kesesuaian teknologi baru dengan nilai, gaya hidup, pengalaman sebelumnya dan kebutuhan pengguna (Bagla \& Sancheti, 2018). Dalam penelitian ini, pengalaman menggunakan suatu teknologi pembayaran yang sudah ada cenderung membantu pengguna melihat tingkat kesulitan dalam penggunaan e-wallet apakah sesuai dengan nilai, gaya hidup, pengalaman dan kebutuhan yang mereka miliki. Maka hipotesis yang diusulkan:

H5: Perceived compatibility berpengaruh secara positif terhadap perceived ease of use pada $e$-wallet.

F. Hubungan Perceived compatibility dan Perceived Usefulness

Dalam penelitian ini, persepsi perceived usefulness mengacu pada sejauh mana pengguna menganggap $e$-wallet memiliki manfaat yang berbeda dengan cara pembayaran yang lain. Misalnya, jika konsumen paham akan manfaat dari teknologi $e$-wallet, maka konsumen tersebut akan cenderung menggunakan teknologi mobile payment (Lu, Yang, Chau, \& Cao, 2011). Oleh karena itu, penelitian ini mengambil hipotesis sebagai berikut:

H6: Perceived compatibility berpengaruh secara positif terhadap perceived usefulness pada $e$-wallet.

G. Hubungan Individual Mobility dan Perceived Ease of Use

Dalam konteks mobile payment, individual mobility sebagai salah satu keunggulan yang dimiliki daripada mobile payment lainnya. Hal tersebut mengacu pada kemampuan penggunaan mobile payment untuk berupaya memenuhi kebutuhannya dalam melakukan pembayaran suatu transaksi dari lokasi dimana saja dan di waktu kapan pun agar dapat memenuhi dan menyederhanakan semua kebutuhan dengan langkah-langkah sederhana (Bagla \& Sancheti, 2018). Oleh karena itu, hipotesis ketujuh dari penelitian ini adalah

H7: Individual mobility secara positif terkait dengan perceived ease of use pada ewallet.

H. Hubungan Individual Mobility dan Perceived Usefulness

Perceived Usefulness dalam penelitian ini mengacu pada sejauh mana e-wallet dipersepsikan memberikan manfaat dalam melakukan aktivitas keuangan tertentu. Seorang individu yang berusaha membetuk pola hidup untuk memenuhi kebutuhan mereka yang mengutamakan fleksibilitas akan memahami manfaat yang diterima saat menggunakan pembayaran seluler (Yen \& Wu, 2016). Dengan demikian, hipotesis kedelapan penelitian ini adalah sebagai berikut:

H8. Individual mobility yang dirasakan berpengaruh secara positif terhadap perceived usefulness pada e-wallet. 


\section{Hubungan Perceived Security dan Intention to Adopt}

Perceived security juga dapat dikonseptualisasikan sebagai kehilangan kendali atas informasi keuangan, pencurian dan kehilangan atau kerusakan yang diberikan kepada perangkat seluler. Kurangnya security akan dianggap sebagai hambatan untuk adopsi mobile wallet (Seetharaman, Kumar, Palaniappan, \& Weber, 2017). Dengan demikian, hipotesis kesembilan penelitian ini adalah sebagai berikut:

H9: Perceived security secara positif memengaruhi intention to adopt pada e-wallet.

J. Hubungan Perceived Ease of Use dan Intention to Adopt

Perceived ease of use dapat didefinisikan sebagai tingkat kepercayaan pengguna dalam menggunakan suatu teknologi yang membutuhkan sedikit usaha untuk melakukannya. Semakin banyak pengguna percaya bahwa untuk menggunakan inovasi hanya membutuhkan upaya minimum, semakin tinggi tingkat kepercayaan mereka bahwa kinerja mereka dapat ditingkatkan dengan menggunakan teknologi dan akan mengadopsi teknologi tersebut (Septiani et al., 2017). hipotesis yang diusulkan pada penelitian ini adalah sebagai berikut:

H10: Perceived ease of use secara positif mempengaruhi intention to adopt pada $e$ wallet.

K. Hubungan Perceived Ease of Use dan Perceived Usefulness

Perceived ease of use mengacu pada perasaan bahwa seseorang memiliki jumlah upaya yang dapat dia terapkan untuk menggunakan sistem tertentu (Matemba \& Li, 2018). Sistem yang mudah digunakan pada akhirnya akan digunakan dengan lebih nyaman. Oleh karena itu, sistem yang dianggap mudah digunakan memungkinkan pengguna untuk lebih mudah menyelesaikan lebih banyak tugas daripada sistem yang lebih sulit (Anjelina, 2018). Oleh karena itu, hipotesis yang diajukan dalam penelitian ini adalah sebagai berikut.

H11: Perceived ease of use secara positif mempengaruhi perceived usefulness pada e-wallet.

L. Hubungan Perceived Usefulness dan Intention to Adopt

Dalam konteks lingkungan online, perceived usefulness adalah sejauh mana keyakinan konsumen akan suatu pembayaran online akan memberikan akses informasi yang berguna, dan memungkinkan pembayaran yang lebih cepat dibandingkan pembayaran secara tradisional (Mun, Khalid, \& Nadarajah, 2017); (Septiani et al., 2017). Maka hipotesis yang diusulkan yaitu:

H12: Perceived usefulness berpengaruh secara positif terhadap intention to adopt pada e-wallet.

M.Hubungan Trust dan Intention to Adopt

Pada penelitian ini, Trust didefinisikan sebagai persepsi positif seseorang terhadap provider mobile payment khususnya Gopay dimana provider akan menepati perjanjian yang mereka tawarkan. Hal tersebut dapat diukur dengan adanya integrity, ability, benevolence. Jika penyedia layanan $e$-wallet memenuhi ketiga hal tesebut, 
konsumen lebih cenderung terlibat dengan transaksi e-wallet (Leong, Hew, Tan, \& Ooi, 2013). Maka hipotesis yang diusulkan yaitu:

H13: Trust berpengaruh positif terhadap intention to adopt pada e-wallet.

\section{Metode Penelitian}

Penelitian ini memakai metode kuantitatif yang berfokus saat pengujian serta pembuktian hipotesis melalui pengumpulan data. Pengumpulan data primer dengan cara penyebaran kuesioner kepada responden penelitian secara online maupun offline. Adapun populasi yang digunakan dalam penelitian ini adalah masyarakat yang mengetahui namun belum pernah menggunakan produk mobile payment gopay. Penelitian ini menggunakan 27 indikator sehingga dibutuhkan 270 sampel. teknik pengambilan sampel yang digunakan adalah menggunakan teknik purposive sampling. Karakteristik yang digunakan dalam penelitian ini adalah responden yang berusia 17 tahun keatas dan pengguna yang belum menggunakan mobile payment namun mengetahui ataupun pernah mendengar tentang gopay. Structural equation modelling (SEM) digunakan sebagai teknik analis data pada penelitian ini dengan menggunakan aplikasi AMOS 22.0.

\section{Hasil dan Pembahasan}

Tabel 1 Hasil Uji Hipotesis

\begin{tabular}{|c|c|c|c|}
\hline Hipotesis & C.R & $\mathbf{P}$ & Keterangan \\
\hline $\begin{array}{c}\mathrm{H1}: \text { Personal innovativeness } \\
\text { ease of use }\end{array} \rightarrow$ perceived & 2,105 & 0,035 & Diterima \\
\hline $\begin{array}{c}\mathrm{H} 2: \text { Personal innovativeness } \\
\text { usefulness }\end{array} \rightarrow$ perceived & 0,936 & 0,349 & Ditolak \\
\hline H3: Subjective norm $\rightarrow$ perceived ease of use & 2,671 & 0,008 & Diterima \\
\hline H4: Subjective norm $\rightarrow$ perceived usefulness & 2,890 & 0,004 & Diterima \\
\hline $\begin{array}{c}\text { H5: Perceived compatibility } \rightarrow \text { perceived ease } \\
\text { of use }\end{array}$ & 3,186 & 0,001 & Diterima \\
\hline $\begin{array}{c}\text { H6: Perceived compatibility } \rightarrow \text { perceived } \\
\text { usefulness }\end{array}$ & 1,151 & 0,250 & Ditolak \\
\hline $\begin{array}{c}\mathrm{H} 7: \text { Individual mobility } \\
\text { use }\end{array} \rightarrow$ perceived ease of & 2,247 & 0,025 & Diterima \\
\hline $\begin{array}{c}\mathrm{H} 8: \text { Individual mobility } \\
\text { usefulness }\end{array} \rightarrow$ perceived & 4.754 & *** & Diterima \\
\hline H9: Perceived security $\rightarrow$ intention to adopt & 4,082 & $* * *$ & Diterima \\
\hline $\begin{array}{c}\text { H10: Perceived ease of use } \rightarrow \text { intention to } \\
\text { adopt }\end{array}$ & 2,283 & 0,022 & Diterima \\
\hline $\begin{array}{c}\text { H11: Perceived ease of use } \rightarrow \text { perceived } \\
\text { usefulness }\end{array}$ & 2,277 & 0,23 & Diterima \\
\hline $\begin{array}{c}\mathrm{H} 12: \text { perceived usefulness } \rightarrow \text { intention to } \\
\text { adopt }\end{array}$ & 4,168 & $* * *$ & Diterima \\
\hline H13: Trust $\rightarrow$ intention to adopt & 4,345 & **** & Diterima \\
\hline
\end{tabular}

Sumber: diolah Pribadi (2021) 
Hipotesis 1 dapat diterima atau membuktikan personal innovativeness secara positif memengaruhi perceived ease of use pada e-wallet. Hasil menampilkan CR hitung 2,105 sehingga telah memenuhi nilai yang disyaratkan yaitu $>1,65$. Kemudian nilai $\mathrm{P}$ yang dimiliki kurang dari 0,05 yaitu 0,035. Hasil hipotesis ini relevan dengan penelitian (Zarmpou, Saprikis, Markos, \& Vlachopoulou, 2012) yang menyatakan bahwa individu yang lebih inovatif menunjukkan bahwa mereka adalah pengguna awal yang percaya pada teknologi baru tidak terlalu rumit.

Hipotesis 2 ditolak atau personal innovativeness tidak memengaruhi perceived usefulness pada e-wallet Hasil menampilkan CR hitung 0,936 sehingga tidak memenuhi nilai yang disyaratkan yaitu $>1,65$. Kemudian nilai $\mathrm{P}$ yang dimiliki lebih besar dari 0,05 yaitu 0,349. Penelitian (Sam, Chatwin, \& Zhang, 2014) dan (Liébana-Cabanillas, Marinkovic, de Luna, \& Kalinic, 2018) yang juga mendapatkan hasil tidak memiliki signifikansi antara antara hubungan personal innovation dan perceived usefulness pada penelitian yang telah mereka lakukan.

Hipotesis 3 dapat diterima atau membuktikan subjective norm secara positif memengaruhi perceived ease of use pada $e$-wallet. Hasil menampilkan CR hitung 2,671 sehingga telah memenuhi nilai yang disyaratkan yaitu $>1,65$. Kemudian nilai $\mathrm{P}$ yang dimiliki kurang dari 0,05 yaitu 0,008 . Hasil hipotesis ini relevan dengan penelitian terdahulu mengenai pengaruh subjective norm terhadap perceived ease of use yang dilakukan oleh penelitian (de Luna et al., 2019) menemukan bahwa subjective norm signifikan terhadap perceived ease of use pada penggunaan m-payment.

Hipotesis 4 dapat diterima atau membuktikan subjective norm tinggi secara positif mempengaruhi perceived usefulness pada e-wallet. Hasil menampilkan CR hitung 2,890 sehingga telah memenuhi nilai yang disyaratkan yaitu $>1,65$. Kemudian nilai $\mathrm{P}$ yang dimiliki kurang dari 0,05 yaitu 0,004. Hasil serupa juga diperoleh dari penelitian (Shankar \& Datta, 2018) yang menyatakan subjective norm berpengaruh terhadap perceived ease of use dalam konteks mobile payment pada remaja di negara India.

Hipotesis 5 dapat diterima atau membuktikan perceived compatibility memengaruhi secara positif terhadap perceived ease of use pada e-wallet. Hasil menampilkan CR hitung 3,186 sehingga telah memenuhi nilai yang disyaratkan yaitu $>1,65$. Kemudian nilai $\mathrm{P}$ yang dimiliki kurang dari 0,05 yaitu 0,001 . Hasil hipotesis ini relevan dengan penelitian terdahulu mengenai pengaruh perceived compatibility terhadap perceived ease of use yang dilakukan oleh (Liu \& Tai, 2016) yang menyatakan bahwa compatibility adalah faktor yang terkait dengan inovasi yang diadopsi untuk layanan mobile payment dengan kebutuhan, gaya hidup pengguna, dan kemampuan untuk mencoba layanan baru.

Hipotesis 6 ditolak atau membuktikan perceived compatibility tidak berpengaruh terhadap perceived usefulness pada e-wallet. Hasil menampilkan CR hitung 1,151 sehingga tidak memenuhi nilai yang disyaratkan yaitu $>1,65$. Kemudian nilai $\mathrm{P}$ yang dimiliki lebih besar dari 0,05 yaitu 0,250. Penelitian (Septiani et al., 2017) menemukan bahwa perceived compatibility tidak mempengaruhi manfaat yang dirasakan karena 
kebutuhan dan gaya hidup pengguna tidak mempengaruhi persepsi mereka tentang kegunaan aplikasi gojek.

Hipotesis 7 dapat diterima atau membuktikan individual mobility mempengaruhi secara positif terkait dengan perceived ease of use pada e-wallet. Hasil menampilkan CR hitung 2,247 sehingga telah memenuhi nilai yang disyaratkan yaitu >1,65. Kemudian nilai P yang dimiliki kurang dari 0,05 yaitu 0,025 . Hasil hipotesis ini relevan dengan penelitian terdahulu mengenai individual mobility berpengaruh terhadap perceived ease of use yang dilakukan oleh (Phonthanukitithaworn, Sellitto, \& Fong, 2016) dalam studi mobile payment adoption mengkonfirmasi pengaruh signifikan dari mobility pada perceived ease of use.

Hipotesis 8 dapat diterima atau membuktikan individual mobility memengaruhi secara positif terkait dengan perceived usefulness pada e-wallet. Hasil menampilkan CR hitung 4,754 sehingga telah memenuhi nilai yang disyaratkan yaitu $>1,65$. Kemudian nilai $\mathrm{P}$ yang dimiliki kurang dari 0,05 yaitu 0,000 . Hasil hipotesis ini relevan dengan penelitian terdahulu mengenai individual mobility berpengaruh terhadap perceived usefulness yang dilakukan oleh penelitian (Liébana-Cabanillas et al., 2018) yang menyatakan bahwa individual mobility secara positif memengaruhi perceived usefulness.

Hipotesis 9 dapat diterima atau membuktikan perceived security secara positif memengaruhi intention to adopt pada e-wallet. Hasil menampilkan CR hitung 4,082 sehingga telah memenuhi nilai yang disyaratkan yaitu $>1,65$. Kemudian nilai $\mathrm{P}$ yang dimiliki kurang dari 0,05 yaitu 0,000. Hasil hipotesis ini relevan dengan penelitian terdahulu mengenai perceived security terhadap intention to adopt yang dilakukan oleh penelitian (de Luna et al., 2019) menyatakan bahwa persepsi keamanan konsumen memang merupakan faktor penting yang harus selalu ditangani sejak awal ketika merancang strategi untuk adopsi sistem pembayaran baru.

Hipotesis 10 dapat diterima atau membuktikan perceived ease of use secara positif memengaruhi intention to adopt pada $e$-wallet. Hasil menampilkan CR hitung 2,283 sehingga telah memenuhi nilai yang disyaratkan yaitu $>1,65$. Kemudian nilai $\mathrm{P}$ yang dimiliki kurang dari 0,05 yaitu 0,022. Hasil hipotesis ini relevan dengan penelitian terdahulu mengenai perceived security terhadap intention to adopt yang dilakukan oleh (Aydin \& Burnaz, 2016) yang berpendapat salah satu faktor utama terkait penerimaan konsumen terhadap suatu sistem adalah seberapa mudah mereka memahami sistem tersebut untuk digunakan.

Hipotesis 11 dapat diterima atau membuktikan perceived ease of use secara positif memengaruhi perceived usefulness pada $e$-wallet. Hasil menampilkan CR hitung 2,277 sehingga telah memenuhi nilai yang disyaratkan yaitu $>1,65$. Kemudian nilai $\mathrm{P}$ yang dimiliki kurang dari 0,05 yaitu 0,023 . Hasil hipotesis ini relevan dengan penelitian terdahulu mengenai perceived ease of use akan memengaruhi perceived usefulness yang dilakukan oleh (Lu et al., 2011) mejelaskan bahwa dalam konteks layanan seluler, Perceived ease of use menentukan nilai pengalaman dari perceived usefulness. 
Hipotesis 12 dapat diterima atau membuktikkan perceived usefulness secara positif memengaruhi terhadap intention to adopt pada e-wallet. Hasil menampilkan CR hitung 4,168 sehingga telah memenuhi nilai yang disyaratkan yaitu $>1,65$. Kemudian nilai $\mathrm{P}$ yang dimiliki kurang dari 0,05 yaitu 0,000 . Hasil hipotesis ini relevan dengan penelitian terdahulu mengenai pengaruh trust berpengaruh terhadap intention adopt yang dilakukan oleh (Bagla \& Sancheti, 2018) yang menyatakan perceived usefulness juga memengaruhi persepsi pengguna saat akan mengadopsi dompet digital di India.

Hipotesis 13 dapat diterima atau membuktikkan trust secara positif memengaruhi terhadap intention to adopt pada e-wallet. Hasil menampilkan CR hitung 4,345 sehingga telah memenuhi nilai yang disyaratkan yaitu $>1,65$. Kemudian nilai $\mathrm{P}$ yang dimiliki kurang dari 0,05 yaitu 0,000. Hasil hipotesis ini relevan dengan penelitian terdahulu mengenai pengaruh trust berpengaruh terhadap intention adopt yang dilakukan oleh (Nag \& Gilitwala, 2019), juga telah membuktikan bahwa kepercayaan memiliki hubungan yang kuat dan signifikan terhadap niat untuk menggunakan dompet digital.

\section{Kesimpulan}

Personal innovativeness berpengaruh terhadap perceived ease of use. Dalam penelitian ini terlihat bahwa tingkat dari persepsi personal innovativeness seseorang berperan penting bagi calon konsumen m-payment gopay dalam merasakan kemudahan penggunaan dari gopay pada aktivitas pembayaran.

Personal innovativeness tidak berpengaruh signifikan terhadap perceived usefulness pada calon konsumen m-payment gopay. responden mempunyai persepsi personal innovativeness yang tinggi namun tetap beranggapan $e$-wallet gopay tidak mempunyai manfaat seperti apa yang mereka harapkan.

Subjective norm berpengaruh signifikan terhadap perceived ease of use pada calon konsumen e-wallet gopay. Pada penelitian ini, individu yang dipengaruhi oleh pendapat anggota masyarakat lain saat mengambil keputusan akan menggunakan e-wallet dan timbul persepsi kemudahan.

Subjective norm berpengaruh signifikan terhadap perceived usefulness pada calon konsumen e-wallet gopay. Seseorang cenderung berinteraksi dengan jaringan sosialnya untuk menanyakan mengenai keputusan adopsi dengan pengaruh sosial normatif dan informatifnya sehingga akan timbul ada atau tidaknya manfaat dari kegunaan dari mpayment gopay.

Perceived compatibility berpengaruh signifikan terhadap perceived ease of use pada calon konsumen e-wallet gopay. perceived compatibility mengacu pada sejauh mana e-wallet dapat disesuaikan sebagai inovasi pembayaran mobile dengan potensi calon pengadopsi berdasarkan nilai, gaya hidup, pengalaman dan kebutuhan dengan melihat tingkat kemudahan dalam penggunaan.

Perceived compatibility tidak berpengaruh signifikan terhadap perceived usefulness pada calon konsumen e-wallet gopay. Responden yang diperoleh memiliki perceived compatibility yang tinggi, namun temuan menjelaskan persepsi responden 
beranggapan e-wallet gopay tidak mempunyai manfaat seperti apa yang mereka harapkan.

Individual mobility berpengaruh signifikan terhadap perceived ease of use pada pada calon konsumen e-wallet gopay karena tingginya kesibukan dan kegiatan sesorang maka semakin tinggi keinginan atas sebuah sistem terkait pembayaran yang dapat membantu dan mempermudah segala kebutuhannya agar lebih efisien namun dengan prosedur yang mudah.

Individual mobility berpengaruh signifikan terhadap perceived usefulness pada calon konsumen e-wallet gopay. Individual mobility seseorang mendorong mereka untuk merasakan manfaat yang tidak didapatkan pada layanan pembayaran lainnya. Seorang individu yang mempersepsikan nilai individual mobility memahami keunikan layanan seluler dan memiliki persepsi yang kuat tentang kegunaan mobile payment.

Perceived security berpengaruh signifikan terhadap intention to adopt pada calon konsumen e-wallet gopay. Kurangnya fitur keamanan, pada m-paymet gopay dapat menjadi alasan yang untuk menolak menggunakan mobile payment.

Perceived ease of use berpengaruh signifikan terhadap intention to adopt pada calon konsumen e-wallet gopay. Provider e-wallet gopay harus menemukan sistem yang cukup mudah untuk digunakan calon konsumen dibandingkan dengan metode pembayaran mereka saat ini.

Perceived ease of use berpengaruh signifikan terhadap perceived usefulness pada calon konsumen e-wallet gopay. Suatu sistem pembayaran yang lebih mudah digunakan pada akhirnya akan menjadi lebih bermanfaat untuk digunakan dalam membantu memenuhi kebutuhan mereka.

Perceived usefulness berpengaruh signifikan terhadap intention to adopt pada calon konsumen e-wallet gopay. seseorang percaya bahwa penggunaan mobile payment gopay akan meningkatkan kinerjanya dan mendapatkan hasil yang diinginkan dalam kegiatan sehari-hari.

Trust berpengaruh signifikan terhadap intention to adopt pada calon konsumen ewallet gopay. Jika persepsi kepercayaan calon konsumen tinggi pada suatu aplikasi ewallet, maka akan semakin besar pula niat konsumen untuk memakai aplikasi tersebut. 


\section{BIBLIOGRAFI}

Acheampong, Patrick, Zhiwen, Li, Antwi, Henry Asante, Otoo, Anthony Akai Acheampong, Mensah, William Gyasi, \& Sarpong, Patrick Boateng. (2017). Hybridizing an extended technology readiness index with technology acceptance model (TAM) to predict e-payment adoption in Ghana. American Journal of Multidisciplinary Research, 5(2). Google Scholar

Anjelina, Anjelina. (2018). Persepsi Konsumen Pada Penggunaan E-Money. Journal of Applied Managerial Accounting, 2(2), 219-231. Google Scholar

Aydin, Gokhan, \& Burnaz, Sebnem. (2016). Adoption of mobile payment systems: A study on mobile wallets. Journal of Business Economics and Finance, 5(1), 73-92. Google Scholar

Bagla, Ramesh Kumar, \& Sancheti, Vivek. (2018). Gaps in customer satisfaction with digital wallets: challenge for sustainability. Journal of Management Development. Google Scholar

de Luna, Iviane Ramos, Liébana-Cabanillas, Francisco, Sánchez-Fernández, Juan, \& Munoz-Leiva, Francisco. (2019). Mobile payment is not all the same: The adoption of mobile payment systems depending on the technology applied. Technological Forecasting and Social Change, 146, 931-944. Google Scholar

De Pascalis, Francesco. (2021). FinTech credit firms: Prospects and uncertainties. In Routledge Handbook of Financial Technology and Law (pp. 119-137). Routledge. Google Scholar

Hatmawan, Aglis Andhita. (2019). Analisis Niat Konsumen Menggunakan M Payment. CAPITAL: Jurnal Ekonomi Dan Manajemen, 3(1), 60-72. Google Scholar

Immanuel, Noel B. (2019). Consumers' Intention to Use Mobile Payment Technology: A Technology Acceptance Model Perspective. Karawang: President University. Google Scholar

Leong, Lai Ying, Hew, Teck Soon, Tan, Garry Wei Han, \& Ooi, Keng Boon. (2013). Predicting the determinants of the NFC-enabled mobile credit card acceptance: A neural networks approach. Expert Systems with Applications, 40(14), 5604-5620. Google Scholar

Liébana-Cabanillas, Francisco, Marinkovic, Veljko, de Luna, Iviane Ramos, \& Kalinic, Zoran. (2018). Predicting the determinants of mobile payment acceptance: A hybrid SEM-neural network approach. Technological Forecasting and Social Change, 129, 117-130. Google Scholar

Liu, Gia Shie, \& Tai, Pham Tan. (2016). A study of factors affecting the intention to use mobile payment services in Vietnam. Economics World, 4(6), 249-273. Google Scholar 
Lu, Yaobin, Yang, Shuiqing, Chau, Patrick Y. K., \& Cao, Yuzhi. (2011). Dynamics between the trust transfer process and intention to use mobile payment services: A cross-environment perspective. Information \& Management, 48(8), 393-403. Google Scholar

Matemba, Elizabeth D., \& Li, Guoxin. (2018). Consumers' willingness to adopt and use WeChat wallet: An empirical study in South Africa. Technology in Society, 53, 5568. Google Scholar

Mun, Yeow Pooi, Khalid, Haliyana, \& Nadarajah, Devika. (2017). Millennials' perception on mobile payment services in Malaysia. Procedia Computer Science, 124, 397-404. Google Scholar

Nag, Amit Kumar, \& Gilitwala, Bhumiphat. (2019). E-Wallet-factors affecting its intention to use. International Journal of Recent Technology and Engineering (IJRTE), 8(4). Google Scholar

Nugroho, Mahendra Adhi, \& Fajar, M. Andryzal. (2017). Effects of technology readiness towards acceptance of mandatory web-based attendance system. Procedia Computer Science, 124, 319-328. Google Scholar

Phonthanukitithaworn, Chanchai, Sellitto, Carmine, \& Fong, Michelle W. L. (2016). A comparative study of current and potential users of mobile payment services. Sage Open, 6(4), 2158244016675397. Google Scholar

Rizal, Muhamad, Maulina, Erna, \& Kostini, Nenden. (2018). Fintech As One Of The Financing Solutions For SMEs. Jurnal Pemikiran Dan Penelitian Administrasi Bisnis Dan Kewirausahaan, 3(2), 89-100. Google Scholar

Sam, Kin Meng, Chatwin, Chris R., \& Zhang, Jing Xin. (2014). Adoption of near field communication for mobile payment: Evidence from Macau. 2014 IEEE International Conference on Industrial Engineering and Engineering Management, 1121-1125. IEEE. Google Scholar

Schierz, Paul Gerhardt, Schilke, Oliver, \& Wirtz, Bernd W. (2010). Understanding consumer acceptance of mobile payment services: An empirical analysis. Electronic Commerce Research and Applications, 9(3), 209-216. Google Scholar

Seetharaman, A., Kumar, Karippur Nanda, Palaniappan, S., \& Weber, Golo. (2017). Factors Influencing Behavioural Intention to Use the Mobile Wallet in Singapore. Journal of Applied Economics \& Business Research, 7(2). Google Scholar

Septiani, Rizky, Handayani, Putu Wuri, \& Azzahro, Fatimah. (2017). Factors that affecting behavioral intention in online transportation service: Case study of GOJEK. Procedia Computer Science, 124, 504-512. Google Scholar

Shankar, Amit, \& Datta, Biplab. (2018). Factors affecting mobile payment adoption 
Saka Wisnu Saputtera

intention: An Indian perspective. Global Business Review, 19(3_suppl), S72-S89. Google Scholar

Yen, Yung Shen, \& Wu, Feng Shang. (2016). Predicting the adoption of mobile financial services: The impacts of perceived mobility and personal habit. Computers in Human Behavior, 65, 31-42. Google Scholar

Zarmpou, Theodora, Saprikis, Vaggelis, Markos, Angelos, \& Vlachopoulou, Maro. (2012). Modeling users' acceptance of mobile services. Electronic Commerce Research, 12(2), 225-248. Google Scholar

\section{Copyright holder:}

Saka Wisnu Saputtera (2022)

First publication right:

Syntax Literate: Jurnal Ilmiah Indonesia

This article is licensed under:

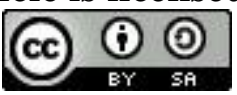

